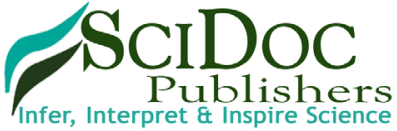

\section{Reasons for Dental Phobia and the Solutions to Overcome}

\section{International Journal of Dentistry and Oral Science (IJDOS) \\ ISSN: $2377-8075$}

\begin{abstract}
Karimi $M^{*}$
Chief Dental Officer, Apple Dental Clinic, Iran.

Everybody might have a reason to have fear from dental procedures. Perhaps that does why, despite suffering from dental problem, most of us have not visited a dentist for a long time. Going to dental office is not a pleasant feeling, and even might come with fear, stress and anxiety. Unaware that it can be easily overcome the fear of dental treatments and unpleasant experiences by going through the treatment without fear and stress.
\end{abstract}

Eight reasons and solutions are listed here to overcome this phobia.

\section{Bad Experience}

Having a bad dental experience in childhood is enough to keep patient away from a dentist for rest of his life.

\section{Solution}

Many bad dental memories are related to childhood and adolescence while still seeing a person with a writhe coat causing anxiety and horror. But being away from childhood, many of the images, sounds, and dental material odors, would be disappear from this ambiguous and terrifying stage. Therefore, there is no reason to be scared of.

The second part of dental bad memories is related to unpleasant experiences with pain and suffering from the dentist's office. Usually this happens when the dental problems are reached to acute phase, and they are forced to go to dentist to relieve from pain and infection. It is natural that in such cases the patient's pain thresholds would significantly reduce and the anesthesia would have late effect, therefore, any dental procedure would become a very painful stimulus.

If you've had a bad experience of presence in dental environment, does not imply that experience would happen again. It is better to discard all old and unpleasant memories of yourself.

If you are not satisfied with his previous dental work, and believe his attitude and dental treatments have caused a bad image in your mind, it is the best to change your dentist.

\section{Fear of Pain}

One reason for having pain during the dental procedure is having very sensitive teeth or periodontal diseases. Thinking about pain during the dental exam is worse than the pain. When the dentist starts working, the patient is experiencing stress and is waiting for the onset of pain.

\section{Solution}

Treatment must be taken before the occurrence of the event, thus, before getting dental pain and acute dental problems, you should refer to a dentist. Choose a dentist who is very friendly and prefer to work with a nonaggressive treatment plan in a quiet environment. Finally, you can ask your dentist before your treatment session to prescribe the proper analgesics and sedatives.

\section{Fear of Injection}

Many people have fear of the dental injections more than visiting the dentists. Watching a fine needle and visualizing how it is entering into the tissues, makes any human being to panic.

\section{Solution}

To eliminate this pain, ask your dentist before injection of the local anesthesia, apply some local anesthesia gel on the injection site. This might help you to not feel the pain during the entering of the needle into the tissues.

Many dentists use painless needles and special injection techniques that greatly reduce the pain of injection. You can close your eyes and comfort yourself. Forget that you are in dentist's office. Take your thoughts to faraway places such as a quiet sandy shore. With this relaxation and meditation, you might not panic when the injection starts.

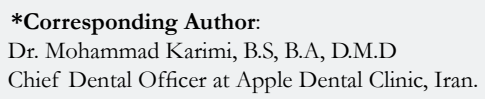




\section{Lack of Control and Dominance on the Treatment}

When you go to dentistry, you should have full confidence in him. Of course, it is hard; you are in a position that you cannot see what is going on around you, and you don't have control over.

\section{Solution}

Before starting the treatment, ask your dentist to explain the process of dental procedure and familiar you with dental instruments. When you know the application and definition of each instrument, there is no reason to panic when you see the instruments.

\section{Dental Drills}

The sound of dental drills looks like the sound of the fingernails dragging on a flat surface. When it is mixed with the sound of suction, it will cause double stress on the patient.

\section{Solution}

Dental drills are working with air. Terrible sound of dental drills is caused by air passing between the blades of the machine. Then, you should not be afraid of the sound of air flow. If the dental drills are new and perfectly greased before using, their screech sound will not be significant.

The main strategy to not hear the sound of dental drills is holding the ear or preferably listening to the light music through the headphones. However, remember that in order to hear your dentist voice clearly, you should not listen to the music too loud.

\section{Being Ashamed of his Oral Health Condition}

One of the reasons people have for not visiting the dentist, embarrassment of their teeth conditions and their bad oral health. They are ashamed of someone to be informed of conditions of their teeth, even a dentist.

\section{Solution}

I always joke these kind of patients that why do you have to be embarrassed by decayed and bad formed teeth while I am making money from filling your decayed teeth. So, keep your head up and proudly tell your doctor that I have many decayed teeth.
Be sure your dentist has seen many teeth worse than yours. Of course, if you postpone your visit to your dentist, your teeth condition would be worsen; For example, a simple decay leads to a root canal therapy.

\section{Unpleasant Odor of Dental Materials}

The materials used for sterilization of dental equipments, have a very strong and special smell which causes stress alone; even before entering into the examination room.

\section{Solution}

If you have a sensitive sense of smell, and the smell of dental material or tooth preparation causing irritation or even disgusting you, you can work with a simple solution to eliminate the unpleasant odors; Perfume yourself or ask your dentist to spray air freshener in the room.

\section{Feeling of Nausea and Suffocation}

During the examination and the treatment, when the dentist put the instrument in your mouth, you might have a bad feeling of gagging and vomiting. People, who are at risk of becoming nauseated, often refuse to go to the dentist; because they have fear of vomiting during the dental examination.

\section{Solution}

If you are very sensitive for approaching an object or instrument to your throat and you get nausea, you should keep in your mind the following suggestions.

First of all, tell your doctor your problem before starting the dental work so he can be prepared for this situation.

Second, with application of local anesthesia on the area of palate and pharynx, the dentist will simply solves this problem.

Finally, I suggest breathing deeply through your nose during the dental procedure and do not pay attention to the feeling of nausea and gagging thoughts. 